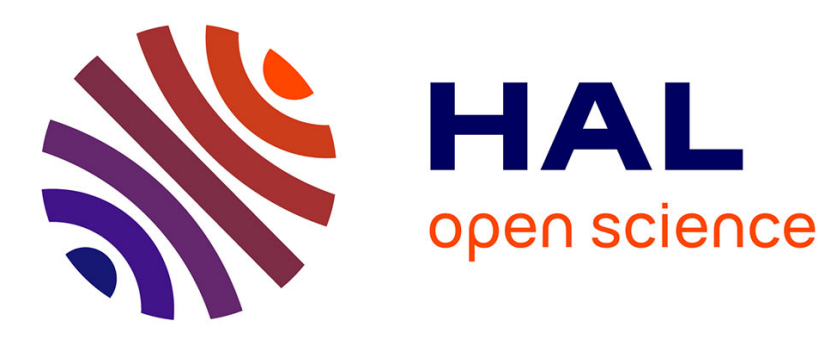

\title{
Nutrition Transition and the Structure of Global Food Demand
}

Christophe C. Gouel, Houssein Guimbard

\section{To cite this version:}

Christophe C. Gouel, Houssein Guimbard. Nutrition Transition and the Structure of Global Food Demand. American Journal of Agricultural Economics, 2019, 101 (2), pp.383-403. 10.1093/ajae/aay030 . hal-02043169

\section{HAL Id: hal-02043169 \\ https://hal.science/hal-02043169}

Submitted on 20 Feb 2019

HAL is a multi-disciplinary open access archive for the deposit and dissemination of scientific research documents, whether they are published or not. The documents may come from teaching and research institutions in France or abroad, or from public or private research centers.
L'archive ouverte pluridisciplinaire HAL, est destinée au dépôt et à la diffusion de documents scientifiques de niveau recherche, publiés ou non, émanant des établissements d'enseignement et de recherche français ou étrangers, des laboratoires publics ou privés. 


\title{
Nutrition Transition and the Structure of Global Food Demand*
}

\author{
Christophe Gouel $^{\dagger 1,2} \quad$ Houssein Guimbard ${ }^{\ddagger 3}$ \\ ${ }^{1}$ Économie Publique, AgroParisTech, INRA, Université Paris-Saclay, 78850, Thiverval-Grignon, France \\ ${ }^{2}$ IFPRI, 1201 Eye St, NW, Washington, DC 20005, USA \\ ${ }^{3}$ CEPII, 20 avenue de Ségur, 75015, Paris, France
}

\begin{abstract}
Estimating future demand for food is a critical aspect of global food security analyses. The process linking dietary changes to wealth is known as the nutrition transition and presents well-identified features that help to predict consumption changes in poor countries. This study proposes to represent the nutrition transition with a nonhomothetic, flexible-in-income, demand system. The resulting model is estimated statistically based on cross-sectional information from FAOSTAT. It captures the main features of the nutrition transition: rise in demand for calories associated with income growth; diversification of diets away from starchy staples; and a large increase in caloric demand for animal-based products, fats, and sweeteners. The estimated model is used to project food demand between 2010 and 2050 based on a set of plausible futures (trend projections and Shared Socioeconomic Pathways scenarios). The main results of these projections are: (1) global food demand will increase by $47 \%$, less than half the growth in the previous four decades; (2) this growth will be attributable mainly to lower-middle-income and low-income countries; (3) the structure of global food demand will change over the period, with a doubling of demand for animal-based calories and a much smaller 19\% increase in demand for starchy staples; and (4) the analysis of a range of population and income projections reveals important uncertainties: depending on the scenario, the projected increases in demand for animal-based and vegetal-based calories range from 74 to $114 \%$ and from 20 to $42 \%$, respectively.
\end{abstract}

Keywords: Bennett's law, food demand, food security, nutrition transition.

JEL classification: D12, Q11.

\footnotetext{
*The authors would like to thank the editor James Vercammen and three anonymous referees, as well as Tamara Ben-Ari, Raja Chakir, Stéphane De Cara, Lionel Fontagné, Lauriane Mouysset, and Hugo Valin for their helpful suggestions. They are grateful to Thomas W. Hertel and Paul V. Preckel for sending them their estimation code.

This is a pre-copyedited, author-produced PDF of an article accepted for publication in the American Journal of Agricultural Economics following peer review. The version of record "Gouel, C. and H. Guimbard (2019). Nutrition Transition and the Structure of Global Food Demand. American Journal of Agricultural Economics, 101(2) 383-403" is available online at: https://doi.org/10.1093/ajae/aay030.

†Corresponding author, christophe.gouel@inra.fr

†houssein.guimbard@ cepii.fr
} 
Food production will have to grow substantially by the middle of the century in order to feed a more populous and richer world (Fouré et al., 2013). A similar challenge has been met in past years with a food supply that has more than tripled since the 1960s. However, given the anticipated adverse impacts of climate change and the degradation of natural resources, there are concerns over the possibility of maintaining this trend (Godfray et al., 2010). Analyzing possible futures for world agriculture requires researchers to analytically capture the main drivers of and constraints to the evolution of demand and supply. This article proposes an approach to quantify possible evolutions in food demand.

Understanding the evolution of global food demand hinges crucially on the likely developments in currently poor countries with low per capita food consumption levels. To help our understanding, we should draw on the insights from the nutrition transition literature. The nutrition transition, as the process by which diets evolve with per capita income and with economic development more generally, informs analyses of the worldwide spread of noncommunicable diseases associated with overnutrition (Drewnowski and Popkin, 1997; Popkin et al., 2012). However, the economic analyses of the structure of global food demand do not use the concept of nutrition transition. Because this concept describes the deterministic patterns observed in the evolution of diets, it also helps to predict food demand in currently poor countries following years of income growth, and thus it is important for an analysis of global food security issues such as the capacity to feed the world's population in the future. Based on the nutrition transition literature, and Engel's and Bennett's laws we have good ideas of how global food demand should evolve with income qualitatively, ${ }^{1}$ but the quantification of this relationship is more elusive and that is the issue addressed in this article. We estimate an economic model of demand that captures some of the stylized facts identified in the nutrition transition literature to enable the predictions about future demand for food. ${ }^{2}$ We exploit the model to make projections of food demand assuming the evolution in prices, gross domestic products (GDP), and populations.

In recent studies of global food security (Havlík et al., 2014; Hertel et al., 2014), the issue of demand for food has received limited attention; the focus has mostly been on accurate representations of the details of the food production process (West et al., 2010; Herrero et al., 2013; Havlík et al., 2014). Most models simply take as a given the Food and Agriculture Organization (FAO) food demand projections (Havlík et al., 2014; Valin et al., 2014). Every few years, the FAO publishes a report on the likely long-run situation in world agricultural markets (Alexandratos, 1988, 1995; Bruinsma, 2003; FAO, 2006; Alexandratos and Bruinsma, 2012). It forecasts food demand at the country level for 32 commodities by first combining demand functions with GDP and population projections, followed then by "several rounds of iterations and adjustments in consultation with specialists on the different countries and disciplines" (Alexandratos and Bruinsma, 2012, Appendix 2). The FAO's role, as an international organization, is to provide predictions of the most likely future food market situation, which might involve adjusting the model's projections based on in-house expertise. However, the downsides to this approach are that the process by definition is nontransparent; it does not allow analysis of alternative scenarios (for example, dietary changes, alternative GDP growth scenarios), nor does it allow improvements by other researchers, because it is not replicable. In contrast, the approach proposed in this article is completely transparent and, because it is based on a statistical estimation, it also allows the quantification of uncertainties. Our approach relies on an existing

\footnotetext{
${ }^{1}$ Bennett's law states that the ratio of calories from starchy staple declines as income increases (Bennett, 1941; Timmer et al., 1983).

${ }^{2}$ The nutrition transition has a much wider scope than the present article, addressing issues such the increased consumption of processed products or the public health consequences of changing diets. We restrict our analysis to the aspects of the nutrition transition that are amenable to an aggregate, country-level approach.
} 
demand system and associated econometric methods and shows how they can be applied fruitfully to the question of modeling global demand for food. The results show that the estimated demand model can generate a credible path of future food demand broadly consistent with FAO projections. While this article does not generate food demand projections as detailed as FAO ones (e.g., because of the assumption of a common demand system for all countries or the focus on seven aggregated food groups), it constitutes a first step toward using the disciplines of demand theory for analyzing global demand for food. With additional methodological developments, it could provide an alternative approach for establishing long-run scenarios of global food demand.

In addition to the FAO's efforts, a few other studies have tried to estimate world demand for food (Cranfield et al., 1998; Yu et al., 2004; Tilman et al., 2011; Gao, 2012; Tilman and Clark, 2014; Bodirsky et al., 2015). Some have proposed transparent, statistically estimated models of food demand (Tilman et al., 2011; Gao, 2012; Tilman and Clark, 2014; Bodirsky et al., 2015). Common to most of these works is that they consider food as an aggregated bundle, analyzing either total demand for food (Gao, 2012), or demand for calories from plant versus animal products (Bodirsky et al., 2015), or demand for calories and proteins (Tilman et al., 2011). These models capture the nonlinearity of demand for food, and they appear to achieve a good fit with total demand for food. However, the high level of aggregation masks the large heterogeneity of demand among food products, making studies like these miss important reallocations among food groups, which are at the heart of the nutrition transition. Because the impact on resources is very different depending on the type of calories consumed, it is crucial to capture this effect in a demand system.

The current work is also related to studies devoted to the estimation of global demand systems. Most estimate a common demand system for all countries based on cross-sectional information (Cranfield et al., 1998, 2002; Yu et al., 2004; Seale and Regmi, 2006). Some deal with food as a commodity group among several others, while others use the estimation explicitly to project long-run food demand (Cranfield et al., 1998; Yu et al., 2004). A limitation of these approaches is that they rely on consumption-level prices for processed products across the world but cannot make the link to the demand for calories. Although this choice is adequate for economic models calibrated at similar levels, it might be difficult to map the products under consideration to the supply and use accounts of primary products in FAOSTAT. Another limitation is that if the distribution margin and the demand for services related to food increases with income (Adamopoulos, 2009), then the overall food budget share may decrease slowly with income even though the underlying demand for calories has already reached saturation level. We draw on this literature for our estimation method and borrow the idea of estimating a common demand system for all countries based on cross-sectional information. However, in order to derive a realistic demand for calories and to potentially link our work to the supply side, we choose to work at the primary product level. This choice is equivalent to assuming that food demand is separable between two components: the primary food products, which are valued at trade prices, and the services related to food (for example, processing, food away from home), which are bundled with the outside good and thus are estimated to be luxury goods. A cross-country estimation of food demand in calories at the final good level is possible now for only a few developed countries for which detailed household-level data are available along with the composition of products (Dubois et al., 2014). Our choice makes possible links to existing global food security models (Havlík et al., 2014; Nelson et al., 2014) by using the demand model directly or by using the elasticities it generates.

Our approach involves a statistical estimation of a global demand system representing demand both 
for calories from various food groups and for a nonfood consumption bundle, based on information for the year 2010. To capture a realistic food demand structure, we use the Modified Implicitly Directly Additive Demand System (MAIDADS, Preckel et al., 2010) which provides sufficient flexibility in relation to income to accommodate known regularities in the nutrition transition and the evolution of food demand. For example, this demand system is able to account for (1) the nonlinearity between demand and income: demand for certain food groups might increase at low levels of income but decrease at high income levels; (2) the reallocation among food groups following Bennett's law (Timmer et al., 1983); and (3) the saturation of demand-i.e. that above a certain income level the demand for calories evolves much less with income (Cirera and Masset, 2010). Having estimated this demand system, we use it to project food demand to 2050. It should be noted that the literature has identified other drivers of dietary changes that, although often correlated with income and prices, are not entirely captured by the exogenous variables of our demand system (income, price, and population): for example, urbanization (Drewnowski and Popkin, 1997) or social dimensions of globalization (Oberländer et al., 2017). By their nature, these drivers present challenges to be accounted for in the framework of a structural demand system and have been neglected in this article.

Our sample includes all food products used for human consumption except stimulants (cocoa, coffee, and tea), spices, and alcohol (the daily per capita caloric demand for these three groups together represented 87 of $2,851 \mathrm{kcal} \cdot \mathrm{capita}^{-1} \cdot \mathrm{d}^{-1}$ at world level in 2010 ), and we use 104 countries for the estimation and 154 for the projections. Our empirical strategy builds on the nutrition transition hypothesis that there are deterministic patterns in the evolution of diets with per capita income across countries. This hypothesis is also consistent with studies that highlight a convergence of food demand in middle-income countries toward the pattern of demand in high-income countries (Pingali, 2007; Khoury et al., 2014). To estimate the demand system, caloric food consumption is taken from FAOSTAT food supply data. Food prices are primarily from trade unit values. A country's nonfood price is its purchasing power parities (PPPs) from the 2011 International Comparison Program (ICP), divided by the nominal exchange rate relative to the United States. GDP per capita in current US dollars is based on the World Development Indicators (WDI). To project food demand, we consider six scenarios: a trend projection and the five Shared Socioeconomic Pathways (SSPs) scenarios (O'Neill et al., 2014). For all scenarios, the GDP and population projections are from EconMap (Fouré et al., 2013).

The estimated model captures well the evolution of the food groups for which consumption increases strongly with income such as animal-based food, oils and sweeteners. Using the model, we characterize how the typical diet evolves with income: it increases from $1,982 \mathrm{kcal} \cdot$ capita $^{-1} \cdot \mathrm{d}^{-1}$, consisting mainly of plants, at a per capita income of $\$ 500$ to $3,116 \mathrm{kcal} \cdot \mathrm{capita}^{-1} \cdot \mathrm{d}^{-1}$, with a $30 \%$ share of animal-based calories, at $\$ 50,000$. Such results, including price and income elasticities underlying this evolution of demand, can be calculated in a spreadsheet provided in online appendix. The estimated model is used also to project food demand between 2010 and 2050, with the following main results: (1) global food demand will increase by $47 \%$, less than half the growth in the previous four decades; (2) this growth will be attributable mainly to lower-middle-income and low-income countries; (3) the structure of global food demand will change over the period, with a doubling of demand for animal-based calories and a much smaller 19\% increase in demand for starchy staples; and (4) the analysis of a range of population and income projections reveals important uncertainties: depending on the scenario, the projected increases in demand for animal-based and vegetal-based calories range from 74 to $114 \%$ and from 20 to $42 \%$, respectively. 


\section{The empirical model}

This section presents the demand system used to represent food demand and the econometric procedure to estimate it.

\section{A global system of demand equations}

To capture the relationship between food demand and income, we use the MAIDADS demand system introduced by Preckel et al. (2010), who estimated a nine-commodity group demand system for the world based on 1996 ICP data. It is a generalization of the AIDADS (An Implicit Direct Additive Demand System) model (Rimmer and Powell, 1992b, 1996), itself a generalization of the linear expenditure system (LES). Many properties of this demand system make it particularly suitable for the present analysis. It is very flexible with respect to income and therefore is able to capture the strong nonlinearity of the relationship between food demand and income. It is effectively globally regular (Cooper and McLaren, 1996): the demand equations are regular for all income levels high enough to cover purchase of a minimum subsistence level. This feature, which is not common to many flexible demand systems, is very important if, as in our analysis, all the countries along the development spectrum are considered. It also ensures that the demand equations remain regular when income is projected beyond current levels. Lastly, this demand system allows the income elasticity of some goods to converge to 0 if income growth is unbounded. This capability is important because food demand saturation is observed at high income levels. Indeed, food demand (i.e., caloric intake plus wasted food) is stable once a country has reached a certain level of income. It is crucial to be able to reproduce demand saturation to avoid projecting unbounded food demand growth.

With the MAIDADS, the demand, $\hat{x}$, for a good is the following function of prices, $p$, and income, $m$ :

$$
\hat{x}_{c i}=\underbrace{\frac{\delta_{i}+\tau_{i} \mathrm{e}^{\omega u_{c}}}{1+\mathrm{e}^{\omega u_{c}}}}_{\begin{array}{c}
\text { Subsistence } \\
\text { consump. level }
\end{array}}+\overbrace{\frac{1}{p_{c i}} \underbrace{\frac{\alpha_{i}+\beta_{i} \mathrm{e}^{u_{c}}}{1+\mathrm{e}^{u_{c}}}}_{\begin{array}{c}
\text { Marginal } \\
\text { budget share }
\end{array}}\left(m_{c}-\sum_{j=1}^{I} p_{c j} \frac{\delta_{j}+\tau_{j} \mathrm{e}^{\omega u_{c}}}{1+\mathrm{e}^{\omega u_{c}}}\right)}^{\text {Discretionary consumption level }},
$$

where $i \in\{1, \ldots, I\}$ indexes the goods, $c \in\{1, \ldots, C\}$ indexes the countries, $\delta_{i} \geq 0, \tau_{i} \geq 0, \omega \geq 0$, $0 \leq \alpha_{i}, \beta_{i} \leq 1$,

$$
\sum_{i=1}^{I} \alpha_{i}=\sum_{i=1}^{I} \beta_{i}=1
$$

and the utility level, $u_{c}$, is defined implicitly by

$$
\sum_{i=1}^{I} \frac{\alpha_{i}+\beta_{i} \mathrm{e}^{u_{c}}}{1+\mathrm{e}^{u_{c}}} \log \left(\hat{x}_{c i}-\frac{\delta_{i}+\tau_{i} \mathrm{e}^{\omega u_{c}}}{1+\mathrm{e}^{\omega u_{c}}}\right)-u_{c}=\kappa .
$$

The parameters can be interpreted as follows. $\delta_{i}, \tau_{i}$, and $\omega$ govern the behavior of the subsistence consumption levels; $\alpha_{i}, \beta_{i}$, and $\kappa$ govern the behavior of the discretionary consumption levels. If $\delta_{i}=\tau_{i}$, subsistence consumption is constant and does not vary with income. $\delta_{i}$ is the asymptotic limit of the subsistence consumption level of good $i$ as income approaches the value of the minimum consumption 
bundle (equal to $\sum_{i=1}^{I} p_{c i} \delta_{i}$ ). Conversely, $\tau_{i}$ is the asymptotic limit of the subsistence consumption level as income grows without bound. If $\delta_{i}>(<) \tau_{i}$, the subsistence consumption of good $i$ decreases (increases) with income. $\omega$ governs the speed of adjustment of subsistence consumption with income and allows it to be different from the speed of adjustment of discretionary consumption, governed by $\kappa$. The interpretation of $\alpha_{i}$ and of $\beta_{i}$ is similar to the interpretation of $\delta_{i}$ and of $\tau_{i}$. If $\alpha_{i}>(<) \beta_{i}$, the marginal budget share converges to $\beta_{i}$ from above (below) as income grows.

The MAIDADS can be derived following Hanoch's (1975) definition of a directly implicit additive utility function:

$$
\sum_{i} F_{i}\left(\hat{x}_{c i}, u_{c}\right)=1
$$

where for the MAIDADS the functions $F_{i}$ take the following form

$$
F_{i}\left(\hat{x}_{c i}, u_{c}\right)=\phi_{i}\left(u_{c}\right) \ln \left(\frac{\hat{x}_{c i}-\gamma_{i}\left(u_{c}\right)}{A \mathrm{e}^{u_{c}}}\right),
$$

where $A>0$ and is substituted elsewhere by $\kappa$ with $\kappa=\ln (A)+1$. The functions $\phi_{i}(\cdot)$ and $\gamma_{i}(\cdot)$ define, respectively, the marginal budget shares and the subsistence consumption levels:

$$
\phi_{i}(u)=\frac{\alpha_{i}+\beta_{i} \mathrm{e}^{u}}{1+\mathrm{e}^{u}} \text { and } \gamma_{i}(u)=\frac{\delta_{i}+\tau_{i} \mathrm{e}^{\omega u}}{1+\mathrm{e}^{\omega u}} .
$$

Maximizing utility, $u_{c}$, subject to (4) and a budget constraint results in demand (1). The AIDADS model is obtained by adding the restriction $\gamma_{i}\left(u_{c}\right)=\delta_{i}=\tau_{i}$. The LES model is obtained from the AIDADS model with the additional restriction $\phi_{i}\left(u_{c}\right)=\alpha_{i}=\beta_{i}$.

From Preckel et al. (2010), MAIDADS income elasticities can be expressed as

$$
\begin{aligned}
& \eta_{c i}=\frac{m_{c}}{p_{c i} \hat{x}_{c i}}\left[\phi_{i}\left(u_{c}\right)+\left(m_{c}-\sum_{j=1}^{I} p_{c j} \gamma_{j}\left(u_{c}\right)\right) \frac{\left(\beta_{i}-\alpha_{i}\right) \mathrm{e}^{u_{c}}}{\left(1+\mathrm{e}^{u_{c}}\right)^{2}} \lambda_{c}\right. \\
&\left.+\frac{\left(\tau_{i}-\delta_{i}\right) \omega \mathrm{e}^{\omega u_{c}}}{\left(1+\mathrm{e}^{\omega u_{c}}\right)^{2}} p_{c i} \lambda_{c}-\phi_{i}\left(u_{c}\right) \sum_{j=1}^{I} \frac{\left(\tau_{j}-\delta_{j}\right) \omega \mathrm{e}^{\omega u_{c}}}{\left(1+\mathrm{e}^{\omega u_{c}}\right)^{2}} p_{c j} \lambda_{c}\right],
\end{aligned}
$$

where $\lambda_{c}$ is the Lagrange multiplier associated with the budget constraint in the consumer problem. It is defined as

$$
\begin{aligned}
\lambda_{c}=-\left\{\sum _ { i = 1 } ^ { I } \left[\frac{\left(\beta_{i}-\alpha_{i}\right) \mathrm{e}^{u_{c}}}{\left(1+\mathrm{e}^{u_{c}}\right)^{2}} \ln \left(\hat{x}_{c i}-\gamma_{i}\left(u_{c}\right)\right)\right.\right. \\
\left.\left.\quad-\phi_{i}\left(u_{c}\right)\left(\hat{x}_{c i}-\gamma_{i}\left(u_{c}\right)\right)^{-1} \frac{\left(\tau_{i}-\delta_{i}\right) \omega \mathrm{e}^{\omega u_{c}}}{\left(1+\mathrm{e}^{\omega u_{c}}\right)^{2}}\right]-1\right\}^{-1}\left(m_{c}-\sum_{i=1}^{I} p_{c i} \gamma_{i}\left(u_{c}\right)\right)^{-1} .
\end{aligned}
$$

One of the potential limits of this demand function is its restricted flexibility in prices (formulas for price elasticities are provided in online appendix). The MAIDADS is a generalization of the LES with additional flexibility with respect to income on subsistence levels and marginal budget shares. However, it has no additional flexibility with respect to prices. As for the LES, there is no degree of freedom corresponding to price elasticities, which are only function of the budget shares and income elasticities. 
But, since the income elasticities can potentially have a rich dynamic with the MAIDADS, this richness translates also to the price elasticities that can present non-monotonic behaviors following those of the income elasticities. For this work, where the emphasis is more on income variations than on price variations, this limit remains of second order, but should be considered if the results were used in another context.

\section{Econometric procedure}

The demand system is estimated using constrained maximum likelihood by adding measurement errors to the demand equations, assuming errors are correlated between goods but not countries. Intervals of confidence and tests are calculated by nonparametric bootstrap with 2,000 replicates following the same steps as in Cranfield et al. (2002). With the exception of a few details, the econometric procedure borrows heavily from previous studies (Cranfield et al., 2002; Preckel et al., 2010) but for completeness is presented here in full.

We do not follow the usual practice for the estimation of demand systems of adding measurement errors to the budget shares. Instead, we assume that the quantities, not the budget shares, are measured with errors. The budget shares of primary food products reach very low levels in high-income countries, while in poor countries they can represent a significant portion of the budget and display a high level of heterogeneity because of the variety of diets. Estimating the demand system by using measurement error on the budget shares would lead to a severe heteroscedasticity with a dispersion decreasing with per capita income. This problem is related to the focus of our analysis: goods whose consumption varies hugely with income, in contrast with most works estimating demand systems where income variations are much lower (see Chavas and Segerson, 1987; Brown and Walker, 1989, for discussions of the stochastic specification of demand systems). Estimation based on the consumption levels produces no heteroscedasticity with respect to income.

Observed consumption levels, $x_{c i}$, are the sum of fitted quantities, $\hat{x}_{c i}$, defined by MAIDADS demand equation (1) and error terms

$$
x_{c i}=\hat{x}_{c i}+\varepsilon_{c i},
$$

where $\varepsilon_{c i}$ is the error term. The disturbances are assumed to follow a multivariate normal distribution and to be distributed independently across observations, but correlated between commodities. Therefore,

$$
\mathrm{E}\left(\varepsilon_{c i} \varepsilon_{s j}\right)=\sigma_{i j} \text { if } c=s \text { and } 0 \text { otherwise. }
$$

Let us define $\boldsymbol{\Sigma}=\left(\sigma_{i j}\right)$ as the covariance matrix across commodities.

This econometric problem amounts to the estimation of a nonlinear system of equations. The $\log$-likelihood of this problem concentrated with respect to $\boldsymbol{\Sigma}$ is (Greene, 2011, Section 14.9.3)

$$
\log L=-\frac{C}{2}[I(1+\log 2 \pi)+\log |\boldsymbol{W}|],
$$

where $\boldsymbol{W}_{i j}=\sum_{c=1}^{C} \varepsilon_{c i} \varepsilon_{c j} / C$, and $\boldsymbol{W}$ is the maximum likelihood estimator of $\boldsymbol{\Sigma}$.

Given that $\boldsymbol{W}$ is symmetric and positive-definite, a Cholesky factorization can be applied: $\boldsymbol{W}=\boldsymbol{R}^{\prime} \boldsymbol{R}$, 
where $\boldsymbol{R}=\left(r_{i j}\right)$ is an upper triangular matrix. The decomposition is imposed via the equation

$$
\sum_{c=1}^{C} \varepsilon_{c i} \varepsilon_{c j} / C=\sum_{k=1}^{I} r_{k i} r_{k j}
$$

along with the restriction

$$
r_{i j}=0 \text { for all } i>j .
$$

Because of its implicit definition, the utility level cannot be substituted out of the demand functions, and it is necessary to estimate its level along with the other unknown parameters. The estimation is conducted based on the following optimization problem:

$$
\max _{\substack{\omega \geq 0, \kappa, \alpha_{i} \geq 0, \beta_{i} \geq 0, \delta_{i} \geq 0, \tau_{i} \geq 0, \hat{x}_{c i}>0, u_{c}, \varepsilon_{c i}, r_{i j}}}-\frac{C}{2}\left[I(1+\log 2 \pi)+\log \prod_{i=1}^{I} r_{i i}^{2}\right],
$$

subject to equations (1)-(3), (9), and (12)-(13). This nonlinear programming problem is implemented in the General Algebraic Modeling System (GAMS) Release 25.0.2 and solved using the CONOPT solver. ${ }^{3}$ To find the solution of this complex nonlinear problem, it is important to provide the solver with good initial values, and therefore the following strategy is adopted. The parameters to estimate are initialized by calibrating the MAIDADS as an LES with marginal budget shares equal to the average budget shares, $\alpha_{i}=\beta_{i}=C^{-1} \sum_{c=1}^{C} p_{c i} x_{c i} / m_{c}$; subsistence consumptions equal to a quarter of the minimum consumptions, $\delta_{i}=\tau_{i}=\min _{c} x_{c i} / 4 ; \kappa=1$; and $\omega=0.01$. Based on this arbitrary calibration, the estimation is carried out in two steps. First an AIDADS is estimated by imposing $\delta_{i}=\tau_{i}$ because it is a simpler version of the MAIDADS with fewer parameters. Then, starting from this solution, the MAIDADS is estimated.

\section{Data}

The approach adopted in the analysis is to use the dietary situation in rich countries to identify a possible food consumption path for poor and emerging countries; therefore we want to capture in one demand system consumption behaviors that are common across countries, bearing in mind that we will be unable to adapt the model to capture countries' idiosyncrasies. To fulfill this objective, we aggregate food products so that the demand for the aggregated food groups behaves similarly across countries. So we need to identify food groups for which there are clear patterns between consumption and income across the development spectrum. In addition to this principle, following insights from the nutrition transition literature, we have tried to aggregate food products with similar nutritional qualities. By emphasizing the common dietary behaviors among countries, our aggregation of food products aims at minimizing the specificities of each country diet that would be dominant at the product level. Nonetheless, some country-specific behaviors will still be present in the data, but because we are using only cross-sectional information, it is not possible to account for them in this article.

The aggregation results in seven food groups (table $\mathrm{S} 3$ in the online appendix for the mapping between food groups and food products). The "cereals, roots, and tubers" group corresponds to starchy staples,

\footnotetext{
${ }^{3}$ Data and programs to replicate the results are available at DOI: 10.15454/9DZLRA.
} 
although it could be argued that bananas and plantains play the same role in some countries. The choice to aggregate cereals, roots, and tubers is based on the logic that they all act as a cheap source of calories derived mostly from carbohydrates, and their consumption tends to decline with income (Grigg, 1996). In some countries (such as those in Asia), cereals will be the main source of caloric demand with roots accounting for less than 5\% of the total; in others (such as those in Middle Africa) roots represent more than $20 \%$ of caloric demand. Aggregating these two types of products limits to the most important element the variability that the model is supposed to explain. The same logic applies to the aggregation chosen for the other food groups. Animal products are present in three groups: "meat and seafood" for the expensive, flesh products; "dairy and eggs" for the cheaper animal-based products; and "oils and fats" for animal fats, butter, and cream. More generally, "oils and fats" contains all separated edible fats, from both animals and plants. "Sugar, sugar crops, and sweeteners" corresponds to sugar, honey and other sweeteners, as well as direct consumption of sugar crops (sugar beets and sugar cane)-characteristic of some sugar-producing countries (such as, Brazil, India, and Pakistan). The group "vegetables and fruits" encompasses all consumption of vegetables and fruits. Other food products are gathered into "pulses, nuts, and oilcrops" of which, at the world level, more than half is crops that are sources of vegetable protein (beans, soybeans, and pulses).

\section{Food consumption}

Food consumption is from FAOSTAT food supply (FAO, 2015). For all countries, FAOSTAT provides an annual breakdown among food products of all food supplies available for human consumption. This breakdown does not correspond to the amount actually consumed, which could be lower because the breakdown includes losses and quantities fed to domestic animals. Food products are aggregated at the level of our food groups according to their per capita caloric values. We use the information on food consumption in tons because prices are available in dollars per ton.

FAOSTAT data on food supplies available for human consumption are expressed in primary-equivalent products, not the potentially processed forms in which the products are consumed. This standardization significantly reduces the number of food products and allows a clear mapping with production or, in our case, with available prices. For example, the quantities of bread consumed are expressed as wheat equivalents using technical coefficients, and added to the other forms of wheat consumption.

Table 1 presents descriptive statistics for the estimation sample. For ease in interpretation, the quantities in this table are expressed in $\mathrm{kcal} \cdot \mathrm{d}^{-1}$, but later in order to scale the prices for the estimation, the quantities are expressed in units of $2,000 \mathrm{kcal} \cdot \mathrm{d}^{-1}$. Starchy staple foods represent by far the largest source of caloric intake, with an average of $1,299 \mathrm{kcal} \cdot \mathrm{d}^{-1}$ over a total of 2,986. These are followed, respectively, by fats, sweeteners, meat, dairy and eggs, vegetables and fruits, and other foods.

\section{Prices}

Food prices primarily are from trade unit values - generally used to proxy for trade prices - corrected by the trade policies in the importing countries. Trade unit values are expressed in current US dollars per ton. They have a wide coverage in terms of products, all tradable ones, and countries. Despite their extensive coverage, however trade unit values are not sufficient to obtain all the prices needed for this study. First, by definition, they exclude products that are not traded over the sample period. Second, trade unit values are calculated as a ratio of trade values to trade weights and this last piece of information is 
Table 1. Descriptive Statistics of the Estimation Sample

\begin{tabular}{|c|c|c|c|c|c|}
\hline \multirow[b]{2}{*}{ Consumption bundle } & \multicolumn{2}{|c|}{$\begin{array}{c}\text { Quantity }\left(x_{c i} \cdot 2,000\right) \\
\left(\mathrm{kcal} \cdot \mathrm{d}^{-1}\right)^{\mathrm{a}}\end{array}$} & \multicolumn{3}{|c|}{$\begin{array}{c}\text { Price }\left(p_{c i}\right) \\
\left(\$ \cdot\left(2,000 \mathrm{kcal} \cdot \mathrm{d}^{-1}\right)^{-1} \cdot \mathrm{y}^{-1}\right)^{\mathrm{b}}\end{array}$} \\
\hline & Mean & $\mathrm{SD}$ & Mean & $\mathrm{SD}$ & World price \\
\hline Cereals, roots, and tubers & 1,299 & 310 & 142 & 68 & 160 \\
\hline Sugar, sugar crops, and sweeteners & 310 & 131 & 170 & 80 & 168 \\
\hline Pulses, nuts, and oilcrops & 113 & 70 & 495 & 342 & 337 \\
\hline Vegetables and fruits & 176 & 78 & 2,706 & 1,204 & 3,381 \\
\hline Oils and fats & 406 & 201 & 147 & 46 & 154 \\
\hline Meat and seafood & 290 & 157 & 2,038 & 875 & 2,596 \\
\hline Dairy and eggs & 225 & 137 & 785 & 450 & 809 \\
\hline \multirow[t]{2}{*}{ All food } & 2,986 & 487 & & & \\
\hline & \multicolumn{2}{|c|}{ Quantity $\left(x_{c i}\right)$} & \multicolumn{3}{|c|}{ Price $\left(p_{c i}\right)$} \\
\hline Non-food ${ }^{d}$ & 163 & 136 & 65 & 30 & \\
\hline
\end{tabular}

Per capita GDP $(\$) \quad 15,173 \quad 17,998$

Notes: a Calculated by aggregating food supply information from FAOSTAT food supply. For the ease of interpretation, food quantities are displayed here in kcal per day, while for estimation they are in 2,000 kcal per day. b Price of 2,000 kilocalories per day for one year of consumption. c Calculated as a weighted mean of the export unit values using as weights the exported quantities. $\quad \mathrm{d}$ The units of the nonfood product are chosen arbitrarily so that the US price is $100 \$$.

not systematically reported. When trade unit values are missing, we use producer prices from FAOSTAT, if available. However, the countries for which trade unit values and producer prices are missing tend to be the same, low income countries, so eventually producer prices contribute only to $1 \%$ of the sample of prices. To reduce the number of missing observations, and to mitigate the influence of outliers, we calculate prices (trade unit values and producer prices) as the average over the three years 2009-2011. If both trade unit values and producer prices are missing, we impute the price from the average world export unit value weighted by the quantities exported, calculated using information for the years 2009-2011. If too many prices are missing for a country and have to be imputed, this country is removed from the estimation sample (see below for the criteria of inclusion). See the online appendix for more details about the missing prices.

The trade unit values are extracted from the Trade Unit Values database (Berthou and Emlinger, 2011), which relies on the tariff-line information used to construct the COMTRADE database. Trade values are from the BACI database (Gaulier and Zignago, 2010). Trade policies are from MAcMap-HS6 (Guimbard et al., 2012). To map FAOSTAT food products to trade data, we use a concordance table available from FAOSTAT website.

We then aggregate our database of food prices to the level for which we have nutritional information from FAOSTAT: primary-equivalent products for crops, livestock, and fish. Many important food products in primary-equivalent form can be mapped to a single corresponding price (for example, "wheat and products" can be mapped to the price for wheat), but some correspond to multiple products (such as, "fruits, other" and "nuts and products"). In these cases, we average the prices, weighted by their share in world trade. This procedure results in a set of data on prices in US dollars per ton that matches the information on food consumption. We go a step further and calculate a price corresponding to our chosen level of aggregation by calculating national expenditure on a given aggregate (as the product of prices in 
US dollars per ton by food consumption in ton from FAOSTAT) and by dividing it by the corresponding number of kilocalories. Then, resulting prices are multiplied by 2,000 and 365 so as to normalize them to the annual cost of a daily consumption of 2,000 kilocalories (following a normalization adopted in Roberts and Schlenker, 2013). Table 1 presents descriptive statistics on these prices. The cheapest sources of calories are "cereals, roots, and tubers" and "oils and fats", closely followed by "sugar, sugar crops, and sweeteners."

These price data present one important limit: these are not consumer prices. There is a margin between the trade prices and the retail prices the consumers face, and this margin is likely to be different depending on country's level of development, which may affect the conclusions of this article. There is limited evidence on how the distribution margin evolves with income. One of the rare studies that addresses this issue, Adamopoulos (2009), shows empirically that the distribution margin for food products between producer and retail prices increases with per capita income for rich countries, but not for poor countries. Adamopoulos (2009) proposes a theoretical explanation for this observation related to the faster increase of labor cost, of which distribution is intensive, compared to this sector TFP. The observation that the distribution margin increases with income only for rich countries implies that the biases from not using consumer prices is likely limited. Indeed, in rich countries food demand is high and insensitive to the price of primary food products. Neglecting the evolution of the distribution margins implies an upward bias on price elasticities that will nonetheless be very low.

In our demand system, demand for nonfood products and services is summarized in one nonfood good. Its price is assumed to be the country's price level index (PLI): the PPPs from the 2011 ICP are divided by the country's nominal exchange rate relative to the United States, the reference country, which has an index level of 100. Thus, the PLI measures the differences in price levels among countries related to consumption of the same basket of goods and services. Since nontraded goods make up a large share of the basket, the index tends to follow labor costs and thus per capita income. Low-income countries have a PLI of less than 100, while the PLI for high-income countries is close to or greater than 100. For the countries that do not participate in the ICP, missing PLIs are imputed using a regression model similar to the one used by the World Bank with the PLI as the dependent variable (The World Bank, 2015, p. 213). The explanatory variables are the ratio of the country's per capita GDP to the per capita GDP of the United States and an interaction term of this ratio with a dummy variable for island economies.

To project future demand, we need projections of future food prices. In the absence of a supply model corresponding to our demand model that could allow the determination of the market-clearing prices, we assume that food prices are fixed at the 2010 average world prices presented in table 1 . We do not take a position on the future evolution of the relative prices of food goods with respect to nonfood goods; therefore, we assume that the United States PLI remains at its initial level of 100. However, we know that in countries experiencing high income growth the prices of nontraded goods will vary greatly over the period. To account for this variation for all countries other than the United States, we calculate the PLI using the previous regression model, with the result that as countries converge to the per capita income level of the United States, their PLIs converge to a similar level.

\section{Countries}

Our sample includes all the countries covered by FAOSTAT but excludes countries with missing information on population, food consumption, or GDP. Also, for the estimation, we exclude some 
countries that might behave as outliers, based on the following criteria. We exclude countries whose population in 2010 was below 1 million; this avoids the inclusion of small countries, often islands, which might have peculiar diets. We exclude countries in which more than $2.5 \%$ of cereal consumption in the years 2009-2011 was based on international food aid; ${ }^{4}$ this avoids the inclusion of countries that are not able to afford their own food consumption, and so for which our theoretical framework is irrelevant. More generally, we use the reliance on food aid as indicating issues such as severe droughts or armed conflicts, affecting local production of food, market mechanisms, but also the quality of FAOSTAT statistics for those countries. We exclude countries with more than $30 \%$ of missing prices in terms of caloric demand. Sudan and South Sudan are excluded because they separated in 2011. Finally, we exclude Madagascar and Mali because the data on these countries present inconsistencies that lead to excessive food budget shares. Our estimation sample includes 104 countries and more than $83 \%$ of the world's population.

Table S4 in the online appendix presents the list of countries included in the estimation sample and used for the projections. Sudan is not included in the estimation sample because of its separation from South Sudan in 2011, but the former unified Sudan is included in the projections because the GDP projections do not distinguish the two countries.

\section{Per capita GDP and population}

We use WDI data (The World Bank, 2016) on per capita GDP for 2010. Unlike most estimations of global demand systems that use per capita GDP in US dollars using PPPs (Cranfield et al., 2002; Seale and Regmi, 2006), our estimations are based on per capita GDP in US dollars based on market exchange rates, because GDP projections are available only for GDP calculated at market exchange rates. ${ }^{5}$

Following all previous studies on global food security issues (e.g., Tilman et al., 2011; Alexandratos and Bruinsma, 2012) we use per capita GDP and not household final expenditures, because projections are available for the former but not for the latter. GDP projections (trend scenario and SSPs) are from EconMap version 2.4 (Fouré et al., 2013). EconMap provides GDP projections for 167 countries up to the year 2100 based on an estimated growth model. We use GDP projections in constant US dollars and convert them to per capita GDP using population projections.

For population data, in order to have consistent GDP and population projections, we use the same sources of population projections as EconMap. For the trend scenario, population data are from World Population Prospects: The 2012 Revision from the UN Population Division (2013). For the SSPs, population data are from the International Institute for Applied Systems Analysis (KC and Lutz, 2017).

\section{Results}

We start by discussing the estimation results and their interpretation. Then, using the estimated model, we characterize how the typical diet evolves with per capita income and project global food demand to 2050.

\footnotetext{
${ }^{4}$ Calculated by combining information from the World Food Programme (2015) and from FAOSTAT food balance sheets.

${ }^{5}$ Since the main effect of using PPPs instead of current dollars is to reduce the spread among countries in per capita income rather than to change the ordering between them, then estimating the MAIDADS using PPPs affects only the speed of convergence of the subsistence consumption and marginal budget shares to their asymptotic values, not the shape of the demand functions. So this would have no effect on the results, except for the difficulties related to the lack of GDP projections in PPPs.
} 


\section{Estimation results}

The estimation results are presented in table 2 with bootstrap 95\% confidence intervals in square brackets. Based on the confidence intervals, it can be seen that all the parameters are precisely estimated. Let us consider first the results for subsistence consumption governed by the parameters $\delta, \tau$, and $\omega$. Two food groups, "cereals, roots, and tubers" and "pulses, nuts, and oilcrops," present subsistence consumption declining with income $\left(\delta_{i}>\tau_{i}\right)$; for all the other food groups and the nonfood bundle subsistence consumption increases with income. For the three most expensive food groups-"vegetable and fruits," "meat and seafood," and "dairy and eggs" $-\delta_{i}$ equals or is very close to 0 , meaning that at very low income levels, these are not considered necessities. The estimate of $\omega$ is significantly greater than 1 , which indicates that subsistence consumption reaches asymptotic levels (i.e., $\tau_{i}$ ) when income grows before the marginal budget shares reach their own asymptotic levels.

Table 2. Estimated Parameters $(\log L=1,027)$

\begin{tabular}{|c|c|c|c|c|c|c|}
\hline & \multicolumn{3}{|c|}{$\omega$} & \multicolumn{3}{|c|}{$\kappa$} \\
\hline & 1.554[ & 1.385 & 1.939] & -0.244[ & -0.616 & 0.294 \\
\hline Consumption bundle & \multicolumn{3}{|c|}{$\alpha$} & \multicolumn{3}{|c|}{$\beta$} \\
\hline Cereals, roots, and tubers & 0.037[ & 0.018 ; & $0.055]$ & $0 \quad[$ & 0 & $0.000]$ \\
\hline Sugar, sugar crops, and sweeteners & 0.033[ & $0.021 ;$ & $0.041]$ & 0.000[ & 0 & $0.000]$ \\
\hline Pulses, nuts, and oilcrops & 0.000[ & 0.000 & $0.009]$ & 0.000[ & 0.000 & $0.001]$ \\
\hline Vegetables and fruits & 0.314[ & $0.242 ;$ & $0.400]$ & 0.002[ & & 0.005 \\
\hline Oils and fats & 0.005[ & 0.000 & $0.016]$ & 0.000[ & 0.000 & $0.000]$ \\
\hline Meat and seafood & 0.270[ & 0.205 ; & $0.352]$ & 0.006[ & $0.004 ;$ & $0.009]$ \\
\hline Dairy and eggs & 0.141[ & 0.110 ; & $0.181]$ & 0.001[ & 0.000 ; & $0.004]$ \\
\hline Non-food & 0.200[ & 0.072 ; & $0.302]$ & 0.990[ & $0.984 ;$ & $0.992]$ \\
\hline Consumption bundle & \multicolumn{3}{|c|}{$\delta$} & \multicolumn{3}{|c|}{$\tau$} \\
\hline Cereals, roots, and tubers & 0.695[ & 0.630 ; & $0.726]$ & 0.499[ & 0.444 ; & $0.529]$ \\
\hline Sugar, sugar crops, and sweeteners & 0.043[ & 0.023 ; & $0.059]$ & 0.167[ & 0.152 ; & $0.179]$ \\
\hline Pulses, nuts, and oilcrops & 0.071[ & 0.060 ; & $0.077]$ & 0.037[ & $0.031 ;$ & 0.048 \\
\hline Vegetables and fruits & 0.034[ & 0.015 ; & $0.042]$ & 0.082[ & 0.070 ; & $0.092]$ \\
\hline Oils and fats & 0.088[ & 0.063 ; & $0.108]$ & 0.280[ & 0.256 & 0.303 \\
\hline Meat and seafood & 0.018[ & $0 \quad$; & $0.025]$ & 0.180[ & 0.162 ; & $0.201]$ \\
\hline Dairy and eggs & $0 \quad[$ & 0 & $0.015]$ & 0.121[ & 0.093 & 0.143 \\
\hline Non-food & 6.011[ & 4.189 ; & $6.915]$ & 229.340[ & 204.817 ; & 257.758 \\
\hline
\end{tabular}

Note: $95 \%$ confidence intervals in square brackets, calculated by nonparametric bootstrap with 2,000 replicates.

The behavior of the marginal budget shares is governed by the parameters $\alpha, \beta$, and $\kappa$. The estimates of $\alpha_{i}$ and $\beta_{i}$ suggest that for all food groups the marginal budget share declines with income. For "pulses, nuts, and oilcrops" and "oils and fats," $\alpha_{i}$ and $\beta_{i}$ are both close to 0 , which implies that the consumption level of these groups is explained mostly by their subsistence consumption. Their total consumption changes with real income but less so with price. For all food groups, estimates of $\beta_{i}$ are very close to 0 . So at high income levels, the marginal budget share of food converges to very small values, and to exactly 0 for "cereals, roots, and tubers." For rich countries, almost all further income increases are spent on 
the nonfood bundle. ${ }^{6}$ However, estimates of $\beta_{i}$ for food are not strictly 0 , so food demand never stops growing —although it grows only slowly—as income increases without bound.

To avoid unbounded food demand, we impose food demand saturation in the estimation by constraining $\beta_{i}$ for food products to be equal to 0 . We test for this restriction using a bootstrap likelihood ratio test. At a $p$-value equal to $94.9 \%$, this restriction cannot be rejected. The parameters estimated with demand saturation are presented in table 3 . This restriction affects mostly the speed of convergence to the asymptotic behavior $(\omega$ and $\kappa)$ and the asymptotic subsistence levels $(\tau)$.

Table 3. Estimated Parameters with Demand Saturation Imposed for Food Products $(\log L=1,016)$

\begin{tabular}{|c|c|c|c|c|c|c|}
\hline & \multicolumn{3}{|c|}{$\omega$} & \multicolumn{3}{|c|}{$\kappa$} \\
\hline & 1.266[ & 1.165 & $1.512]$ & -1.016[ & -1.058 & -0.182 \\
\hline Consumption bundle & \multicolumn{3}{|c|}{$\alpha$} & \multicolumn{3}{|c|}{$\beta$} \\
\hline Cereals, roots, and tubers & 0.049[ & 0.024 & $0.066]$ & 0 & & \\
\hline Sugar, sugar crops, and sweeteners & 0.033[ & 0.019 & $0.037]$ & 0 & & \\
\hline Pulses, nuts, and oilcrops & 0.000[ & 0.000 & $0.010]$ & 0 & & \\
\hline Vegetables and fruits & 0.428[ & 0.316 & $0.491]$ & 0 & & \\
\hline Oils and fats & 0.013[ & 0.001 & $0.024]$ & 0 & & \\
\hline Meat and seafood & 0.324[ & 0.224 & $0.380]$ & 0 & & \\
\hline Dairy and eggs & 0.154[ & 0.115 & $0.189]$ & 0 & & \\
\hline Non-food & $0 \quad[$ & 0 & 0.190] & 1 & & \\
\hline Consumption bundle & \multicolumn{3}{|c|}{$\delta$} & \multicolumn{3}{|c|}{$\tau$} \\
\hline Cereals, roots, and tubers & 0.677[ & 0.609 & 0.707] & 0.476[ & 0.431 & 0.507 \\
\hline Sugar, sugar crops, and sweeteners & 0.057[ & 0.047 & $0.076]$ & 0.193[ & 0.179 ; & 0.202 \\
\hline Pulses, nuts, and oilcrops & 0.067[ & 0.056 & $0.072]$ & 0.043[ & 0.038 & 0.053 \\
\hline Vegetables and fruits & 0.029[ & 0.012 & $0.040]$ & 0.094[ & 0.085 & 0.103 \\
\hline Oils and fats & 0.077[ & 0.053 & $0.100]$ & 0.319[ & 0.303 & 0.336 \\
\hline Meat and seafood & 0.013[ & 0 & $0.024]$ & 0.233[ & 0.222 & 0.246 \\
\hline Dairy and eggs & $0 \quad[$ & 0 & $0.015]$ & 0.164[ & 0.140 & 0.189 \\
\hline Non-food & 0 & 0 & 4.692] & 318.441[ & 295.889 ; & 346.164 \\
\hline
\end{tabular}

Note: $95 \%$ confidence intervals in square brackets, calculated by nonparametric bootstrap with 2,000 replicates.

\section{Evolution of the typical diet}

Our estimated demand system provides a good representation of the broad evolution of food consumption with income. The overall fit is summarized in figure 1 which plots observed food consumption against per capita income, for each food group, along with the estimated demand functions evaluated at the average world price. To accommodate the patterns observed in the data, the demand functions are estimated to be strongly nonlinear. For all food groups except "cereals, roots, and tubers" and "pulses, nuts, and oilcrops" which present a hump-shaped pattern, consumption levels increase with income before reaching a plateau. The caloric consumption plateau is at an annual income of around $\$ 25,000$ per capita (similar to income in

${ }^{6}$ This result is not unique to this article. Values of $\beta_{i}$ estimated to be close or equal to 0 for food in AIDADS and MAIDADS can also be found in Rimmer and Powell (1992a), Cranfield et al. (2002), and Preckel et al. (2010). 
Greece, Portugal, and the Republic of Korea in 2010). Stabilization of food demand at high income levels stems from the demand saturation imposed during the estimation. The gray lines in figure 1 represent alternative demand functions plotted using parameters from bootstrap replicates. They are close to the central estimates and of a similar shape, which illustrates the precision of the statistical estimations. Only demand for "dairy and eggs" presents a noticeable uncertainty, with many alternative demand functions located above the central curve. In what follows, we use the bootstrap demand functions to assess the uncertainty surrounding the demand projections.
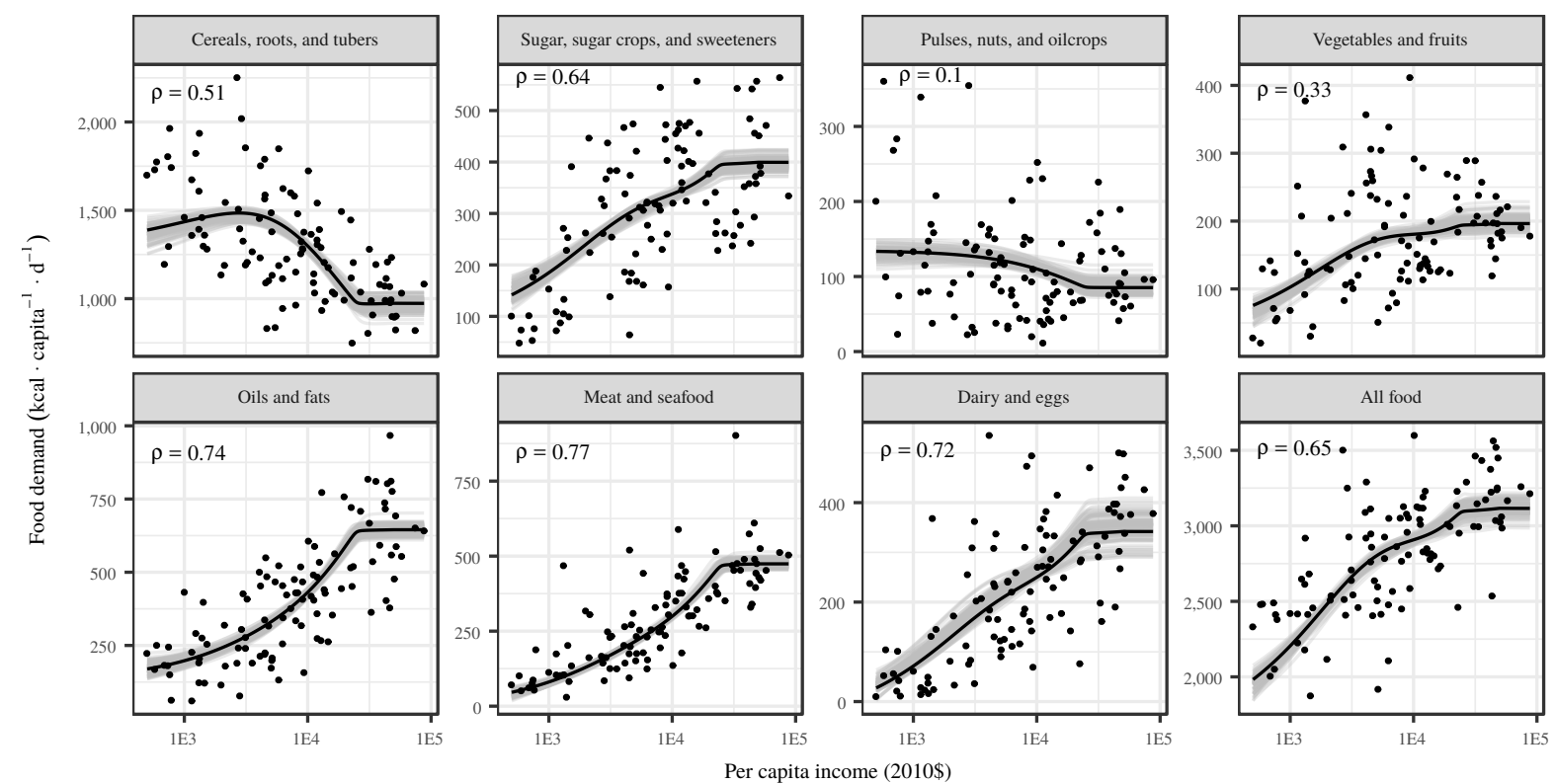

Figure 1. Observed and fitted (at world prices) caloric demand. The gray lines represent fitted caloric demand using the parameters from 100 bootstrap replicates. $\rho$ is the correlation coefficient between the observed values and the fitted values obtained using a 10-fold cross-validation strategy.

Figure 1 displays a correlation coefficient $(\rho)$ between observed and fitted (using local prices) consumption. To avoid assessing the model on within-sample predictions, $\rho$ is calculated using a 10-fold cross-validation strategy. The estimation sample is randomly partitioned into 10 roughly equal subsamples. Each subsample is removed in turn for testing: the estimation is carried on the 9 remaining subsamples and the prediction is done only for the testing subsample. When the 10 rotating estimations have been done, the prediction for the validation subsamples are gathered and the correlation coefficients are calculated. The demand functions correctly capture the relationship between food demand and income with correlation coefficients of between 0.51 and 0.77 , except for "pulses, nuts, and oilcrops" and "vegetables and fruits," with correlation coefficients respectively equal to 0.1 and 0.33 . The low correlation for "pulses, nuts, and oilcrops" might be explained by the fact that this is a residual group that includes all food products that do not fit into the other, larger groups. The limited performance of the groups "pulses, nuts, and oilcrops" and "vegetables and fruits" might also reflect the large heterogeneity across countries in the consumption of the foods in this group and the fact that their consumption is explained very little by income and price variations, and possibly more by culture and food preferences. Three groups-separated fats and the two groups of animal-based products, "meat and seafood" and "dairy and eggs"—-stand out as particularly well represented by the estimated demand system with correlation coefficients greater than 0.7 . 
Using the estimated demand system, we can identify how the typical diet evolves with income. Figure 2 plots the relationship between the demand for each food group and per capita income, obtained by applying the estimated demand system to the average world prices and various levels of per capita income. ${ }^{7}$ The dashed line in the "oils \& fats" polygon separates vegetal-based and animal-based fats, based on the average world share of each fat. ${ }^{8}$ At a low income level of $\$ 500$ per capita, the majority of the caloric demand comes from starchy staples, at close to $1,400 \mathrm{kcal} \cdot \mathrm{capita}^{-1} \cdot \mathrm{d}^{-1}$ for a total of 1,982 $\mathrm{kcal} \cdot \mathrm{capita}^{-1} \cdot \mathrm{d}^{-1}$. The contribution of starchy staples first increases with income, but less so than the other food groups combined, generating diet diversification as income increases. Demand for starchy staples decreases with income after an annual income threshold of around $\$ 2,800$ per capita, and the diet diversifies further. Because demand for calories from plants increases up to an income of $\$ 5,400$ per capita, the decline in demand for starchy staples is more than compensated by the increase in fats and sweeteners, and to a lesser extent, vegetables and fruits. Demand for animal-based food shows a marked increase with income, from $103 \mathrm{kcal} \cdot \mathrm{capita}^{-1} \cdot \mathrm{d}^{-1}$ for per capita income of $\$ 500$ to $926 \mathrm{kcal} \cdot \mathrm{capita}^{-1} \cdot \mathrm{d}^{-1}$ for per capita income of $\$ 50,000$. The pattern described here is consistent with the patterns reported in the literature on the nutrition transition as countries get richer (Drewnowski and Popkin, 1997).

Another way of analyzing the model's results is to consider its prediction of income elasticities. Income elasticities calculated using equation (7) and evaluated at world prices are presented in table 4 for five different levels of per capita income. ${ }^{9}$ Consistent with demand saturation, all income elasticities converge to 0 for very high levels of income. At a per capita income of $\$ 500$, the highest food income elasticity is for "dairy and eggs," followed by "meat and seafood" and "vegetables and fruits." With income increasing, "meat and seafood" becomes the food group with the highest elasticity. Asymptotically, as the budget share of food would reach 0 , the income elasticity of the nonfood bundle would reach 1 .

The income elasticities express differently the previous findings about the evolution of the typical diet. However, they have the advantage to be comparable to available estimates. Calorie-income elasticities have been studied extensively in the past three decades and two meta-analyzes of this literature have been recently published (Ogundari and Abdulai, 2013; Zhou and Yu, 2014). Ogundari and Abdulai (2013) report an average calorie-income elasticity of 0.31 , a minimum of 0.0004 and a maximum of 0.97 . Zhou and $\mathrm{Yu}(2014)$ have a similar average elasticity of 0.35 , with a standard deviation of 0.23 , and confirm that the elasticity decreases with income. From these surveys, the income elasticities estimated in this article for all calories appear to be in the lower part of the available estimates but within the variability of this literature. Lower elasticities than this literature should have been expected. Calorie-income elasticities come usually from estimations on household-level data. We should expect country-level estimates to be lower because of a composition effect: part of the population may have high income level and have already reached food saturation.

${ }^{7}$ This figure is an alternative and modern version of a representation proposed as early as 1969 by the FAO (Périssé et al., 1969), and updated by Drewnowski and Popkin (1997).

${ }^{8}$ The observed share of animal-based fats in all fats increases slowly with income but, while significant, the relationship explains little of the variations, so for simplicity the average world share is used.

${ }^{9}$ Income and price elasticities for any combination of prices and income can be calculated using the spreadsheet provided in the online appendix. 


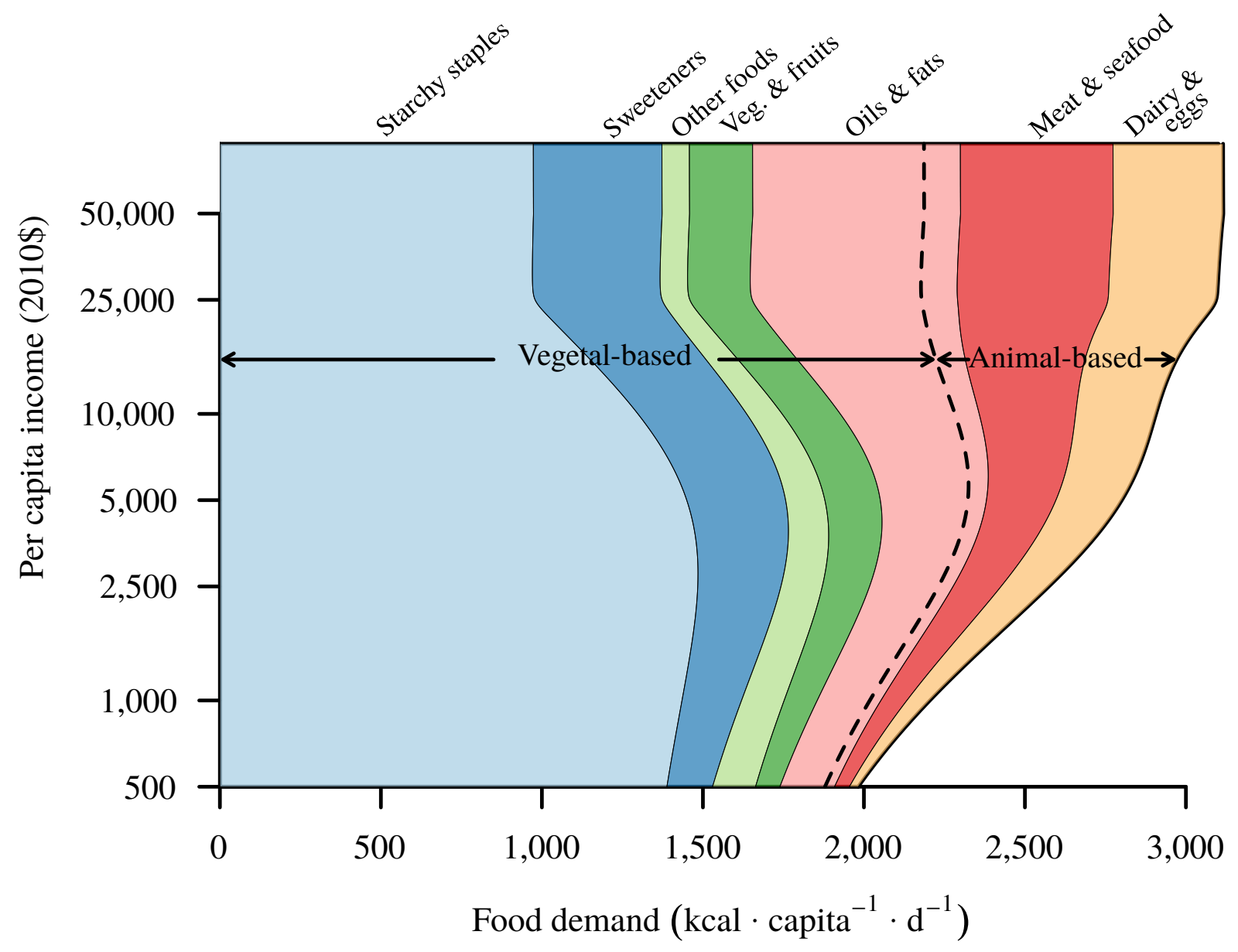

Figure 2. Relation between demand for each food group and per capita income

Table 4. Income Elasticities Calculated at World Prices

\begin{tabular}{lrrrrc}
\hline & \multicolumn{5}{c}{ Per capita income (2010\$) } \\
\cline { 2 - 6 } Consumption bundle & 500 & 1,000 & 5,000 & 10,000 & 50,000 \\
\hline Cereals, roots, and tubers & 0.05 & 0.05 & -0.10 & -0.30 & 0 \\
Sugar, sugar crops, and sweeteners & 0.37 & 0.40 & 0.18 & 0.12 & 0 \\
Pulses, nuts, and oilcrops & -0.01 & -0.02 & -0.11 & -0.24 & 0 \\
Vegetables and fruits & 0.44 & 0.44 & 0.13 & 0 & 0 \\
Oils and fats & 0.19 & 0.26 & 0.39 & 0.50 & 0 \\
Meat and seafood & 0.87 & 0.76 & 0.52 & 0.56 & 0 \\
Dairy and eggs & 1.95 & 1.05 & 0.36 & 0.29 & 0 \\
Vegetal-based & 0.09 & 0.11 & 0.01 & -0.08 & 0 \\
Animal-based & 0.96 & 0.78 & 0.44 & 0.44 & 0 \\
All food & 0.14 & 0.17 & 0.08 & 0.03 & 0 \\
Non-food & 2.52 & 1.52 & 1.15 & 1.08 & 1.03 \\
\hline
\end{tabular}

Note: Aggregate income elasticities (vegetal-based, animal-based, and all food) obtained by weighting the income elasticity of all food groups in the total, allocating the "oils and fats" group between vegetal and animal based on the average world share of animal-based fats in all fats. 


\section{Projecting food demand to 2050}

Using the estimated demand functions and trend projections for GDP and population, we now project world food demand over the period 2010-2050. To remove any effect of price changes and to focus on population and income effects, domestic food prices are assumed to stay level with 2010 world prices (table 1), but future work could link the demand model to a supply model in order to render prices endogenous. Table 5 details changes to demand between 2010 and 2050, and figure S1 in the online appendix plots annual projections up to 2100 . Consumption of all food groups increases over the period, albeit at different rates. Total caloric food consumption rises over the period by $47 \% \pm 5 \%$ but starchy staples and pulses grow by only $19 \% \pm 3 \%$ and $18 \% \pm 5 \%$, respectively. The bulk of this increased consumption is accounted for by animal-based products, fats, and sweeteners. Overall demand for food increases by $0.97 \%$ per year, much lower than the $2.01 \%$ over the four decades prior to 2010 . The lower consumption growth can be explained in part by the slowdown in world population growth which decreases from $2.44 \%$ to $1.74 \%$ (see table S5 in the online appendix for the past and assumed future growth rates). The remainder is due probably to the fact that significant parts of world population have already reached high per capita consumption levels that, because of demand saturation, leave little scope for further increases.

Table 5. Decomposition of Food Demand Change 2010 to 2050 into Population and Income Effects (Percentage Change) for the Trend Projection

\begin{tabular}{lrrc}
\hline Consumption bundle & \multicolumn{1}{c}{ Total } & \multicolumn{1}{c}{$\begin{array}{c}\text { Income } \\
\text { effect }\end{array}$} & $\begin{array}{c}\text { Population } \\
\text { effect }\end{array}$ \\
\hline Cereals, roots, and tubers & $18.5 \pm 3.4$ & $-16.1 \pm 2.4$ & 37.2 \\
Sugar and sweeteners & $62.3 \pm 9.6$ & $23.8 \pm 7.5$ & 29.2 \\
Pulses, nuts, and oilcrops & $18.4 \pm 4.9$ & $-16.1 \pm 4.2$ & 38.4 \\
Vegetables and fruits & $54.2 \pm 14.4$ & $16.3 \pm 11.0$ & 29.5 \\
Oils and fats & $91.9 \pm 5.2$ & $51.0 \pm 4.4$ & 27.5 \\
Meat and seafood & $11.0 \pm 11.1$ & $68.3 \pm 9.0$ & 23.4 \\
Dairy and eggs & $89.8 \pm 22.8$ & $48.8 \pm 18.3$ & 23.8 \\
\hline Vegetal-based & $36.2 \pm 4.2$ & $-0.1 \pm 3.0$ & 34.6 \\
Animal-based & $99.0 \pm 14.0$ & $58.2 \pm 11.3$ & 23.4 \\
\hline All food & $47.1 \pm 5.3$ & $10.0 \pm 4.0$ & 32.7 \\
\hline
\end{tabular}

Note: Central estimation and standard deviation calculated using bootstrap replicates where applicable.

To distinguish the various effects at play, table 5 decomposes changes to food demand into population and income effects. The decomposition is done as follows. The income effect is obtained by increasing only per capita income while population stays at its 2010 level. For the population effect, only population is increased. To make the three columns comparable, in all columns the benchmark situation in 2010 is not the actual consumption levels, but the levels predicted by the model. Population growth is the most important driver of the overall increased demand but does not generate much reallocation of consumption among food groups. Based on population growth, demand increases by between $23 \%$ and $38 \%$ for all food groups, with higher growth of vegetal-based calories due to the concentration of population growth in countries with high shares of these calories (low-income countries). Meanwhile, the effect of income growth leads to an important reallocation of food demand away from starchy staples and pulses toward 
fats, animal-based products, and sweeteners. Income effects are related to changes in demand only in developing countries, since per capita demand for food is already high in developed countries and is unlikely to increase much more (table S6 in the online appendix shows the contribution to growth in food demand of each country group). Based only on income effects, the change in total demand for vegetal-based calories is not significantly different from 0 within the period 2010 to 2050; the increase in total food demand comes only from animal-based food. The combination of population and income effects leads to a marked $99 \% \pm 14 \%$ increase for animal-based food but also to a significant increase of $36 \% \pm 4 \%$ for vegetal-based food, explained by a combination of diet reallocation toward fats and sweeteners, and population growth.

In addition to quantifying the role of the various macro drivers, and the uncertainties arising from the statistical procedure, we quantify the uncertainties related to the underlying economic and demographic projections. In the absence of joint probabilistic GDP and population projections, these uncertainties are analyzed in the literature based on scenarios such as the SSPs (O'Neill et al., 2014). The SSPs scenarios will also be used for facilitating the comparison with other studies projecting world food demand. They use macro-assumptions that are usually different from our trend assumptions but that can be related to one of the SSPs. The SSPs have been developed in climate change research to provide plausible narratives of the future evolutions of society and ecosystems. The different scenarios are characterized by the different challenges for adaptation and mitigation under consideration. They differ regarding the evolution of technologies, preferences, urbanization, global institutions, or demography. Given our purpose, we limit the comparison between scenarios to the drivers that can be quantified easily and that make sense with respect to the present model—income and population-and neglect the other potential drivers. We take the GDP and population projections for the SSPs from Fouré et al. (2013, growth rates available in table S7 in the online appendix). The scenario SSP2 (nicknamed "Middle of the Road") is close to our trend scenario and among the SSPs is a scenario with medium population growth and low-medium per-capita-GDP growth $(2.37 \%)$. There are two scenarios with low population growth: SSP5 ("Conventional Development"), which is associated to a high per-capita-GDP growth rate averaging $3.1 \%$ over the period, and SSP1 ("Sustainability"), with a medium growth rate of $2.7 \%$. The scenario SSP3 ("Fragmentation") assumes high population growth, from low- and middle-income countries, and low per-capita-GDP growth rates, with a world average of $1.76 \%$. Finally, SSP4 (“Inequality") features medium growth in population (but high in low-income countries) and in per capita GDP (2.42\%).

Figure 3 depicts the variations in changes to food demand associated with these plausible alternative futures (decomposition into population and income effects provided in table S8 in the online appendix). The results differ significantly between scenarios, with increased demand for calories from all foods ranging between $33 \%$ and $49 \%$. At the 2050 horizon, the uncertainty over projections is much lower for population than for GDP. However, most of the uncertainty about population growth is concentrated in lower-middle-income and low-income countries, which currently are in the early phases of the nutrition transition. Consequently, the population effect explains most of the differences in total food demand across scenarios, with the income effect more important for explaining the reallocation among food groups. Except for some cases, the alternative projections present the patterns described for the trend projection. In particular, despite large variations in the growth rates, the result that total final demand for food is more driven by population growth than by income growth holds across scenarios. Among the exceptions are the starchy staples. Under two low-population-growth scenarios (SSP1 and SSP5), demand for starchy staples is projected to decline rather than follow the $19 \%$ increase trend. The respective contributions 
of vegetal- and animal-based food in food demand growth are also subject to important uncertainty. In a scenario of high income growth and low population growth (SSP5), demand for animal-based food increases hugely, by $114 \%$, while increased demand for vegetal-based food remains comparatively modest, at $21 \%$. A scenario of low income growth and high population growth (SSP3) favors higher demand for vegetal-based food $(+42 \%)$, although animal-based food demand continues to show the highest growth $(+81 \%)$.

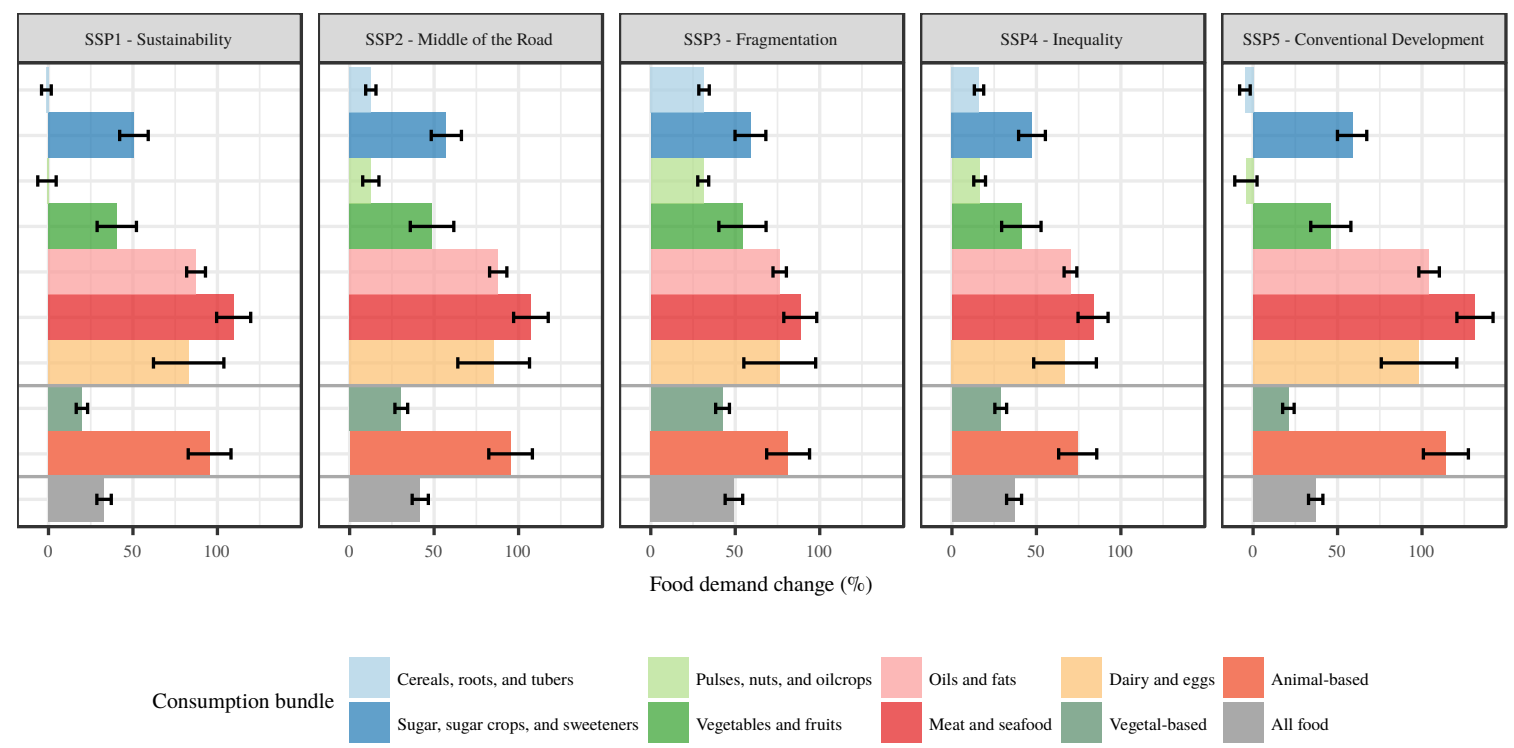

Figure 3. Food demand change 2010 to 2050 for the five Shared Socioeconomic Pathways

We can compare our projections with those of previous studies. Food demand projections from alternative sources differ in their base year, food groups, and macro or price assumptions, which makes formal comparison problematic. Nevertheless, we can assess the similarities among general trends. Our projections are in line with the most recent FAO projections (Alexandratos and Bruinsma, 2012): between 2005 and 2050, they project an increase of 54\% for all food, 50\% for vegetal-based food, and $76 \%$ for animal-based food (reported in Valin et al., 2014). An important difference is related to the type of calories consumed: we project a lower increase in calories from plants and a higher increase in calories from animals. This difference might be related to the FAO's assumption of low economic growth, which is closer to our SSP3 scenario than to our trend estimate. Our SSP3 projections $(+42 \% \pm 4 \%$ and $+81 \%$ $\pm 13 \%$ ) are indeed very close to FAO's ones (see figure 3 and table S8 in the online appendix for the SSP3 projections). Though our projections agree broadly with those of the FAO, they are more discrepant with the food demand projections from the economic models participating in the Agricultural Model Intercomparison and Improvement Project (Valin et al., 2014). Under an SSP2 scenario, these models' projected changes in demand for animal-based products tend to be similar to ours, but they predict much larger demand increases for vegetal-based products. This outcome is likely explained by the fact that negative income elasticities are the exception in most of these models, while decreased consumption of starchy staples with income is a well-established stylized fact (Timmer et al., 1983; Cirera and Masset, 2010), known as Bennett's law (Bennett, 1941), that emerges in our model beyond a threshold income level. In addition, the specifications adopted in some of these models imply that food demand never 
reaches a saturation level and increases continually with income. Demand saturation is absent also from the specification in Bodirsky et al. (2015) where food demand in Europe is predicted to exceed 3,800 $\mathrm{kcal} \cdot \mathrm{capita}^{-1} \cdot \mathrm{d}^{-1}$ in 2050.

Demand saturation is important in our approach to avoid ever-increasing food demand with increasing income, but its interpretation requires a comment. Demand saturation does not necessarily imply perfectly stable diets in the future beyond a certain per capita income level. In recent decades, in the United States and other developed countries, diets have changed, for example with decreased consumption of red meat in favor of poultry meat. No links have been made between these changes and increased per capita income. It is likely that a part of these changes is attributable to price changes and a part to shifts in preferences, that is, shifts in demand functions, related potentially to health issues, demand for convenience, and other concerns (Haley, 2001). These shifts in preferences are unlikely to be predictable, so in the context of projecting future demand it would seem sensible to assume a stable diet. If we want to account for future shifts, this could be done by acknowledging their uncertainty. Using longitudinal data, one could estimate the probability distribution of past diet changes and use this distribution to make probabilistic projections of food demand that account for possible changes.

\section{Conclusion}

This article has demonstrated how a demand system can be used to reproduce the most salient features of the nutrition transition: diversification of diets away from starchy staples as per capita income increases, and a shift toward other food groups, except pulses. As income grows, the most important consumption increases are observed for animal-based products, followed, respectively, by fats, sweeteners, and vegetables and fruits.

The estimated demand system is also useful to project the likely future of food demand. The main results of our projections to 2050 are that (1) food demand will increase by $47 \%$, representing less than half of the growth experienced in the four decades before 2010; (2) this growth will come mainly from developing countries because, in high-income countries, food demand is already at high per capita levels and population growth will be low; (3) growth in starchy staples will be small at 19\%, supported by population increases because per capita consumption is predicted to decrease while demand for animal-based food will double increasing the global share of animal-based calories from 17\% in 2010 to $23 \%$ in 2050; and (4) these projections present large uncertainties that are neglected in related studies: under alternative plausible futures for GDP and population, demand for animal-based calories increases between $74 \%$ and $114 \%$.

This work is a first methodological step toward capturing in an economic model the main features of the nutrition transition. However, some of its weaknesses must be noted to understand the limitations of the forecasts it produces, as well as the possible improvements. Two main caveats must be mentioned. One is related to the fact that it is based on a cross-sectional analysis. The nutrition transition is a dynamic concept describing how diets evolve with per capita income. But since for most countries, longitudinal data on food consumption spanning very different income levels are not available, working on this subject often involves combining cross-sectional and longitudinal information (e.g., Drewnowski and Popkin, 1997). In the present article, the cross-sectional dimension is essential because it allows us to predict the future consumption of currently poor countries based on the current consumption of richer countries. Adding the longitudinal dimension would be a challenging econometric task because of the nonlinearity 
of the model. Without the longitudinal dimension, a common demand system for food must be used for all countries. The model captures the global pattern of the nutrition transition correctly, but there is significant heterogeneity among national diets that is not accounted for. For similar high levels of income, there are countries such as France and the United States, with respective daily food demand of 3,449 and 3,374 $\mathrm{kcal} \cdot \mathrm{capita}^{-1} \cdot \mathrm{d}^{-1}$, and countries such as Japan and Spain, with respective daily food demand of 2,535 and 2,996 kcal.capita ${ }^{-1} \cdot \mathrm{d}^{-1}$. There are comparable differences among poorer countries. Part of the large differences in consumption among rich countries likely stems from cultural preferences, which we are forced to neglect in a cross-sectional analysis. Another implicit assumption related to the cross-sectional analysis is that the speed of diet convergence observed across countries is the same as the one observed across time for a given country. While we do not have evidence of the contrary, this is a source of potential biasedness that should be kept in mind.

Another caveat is that we do not account for reallocation within food groups. For example, consumption of starchy staples decreases with income beyond a certain income level, but for some cereals and tubers, consumption may decrease less than for the others or might even increase with income. Economic growth is accompanied by urbanization, and modern retailing and food distribution, which have major impacts on food consumption. Roots and tubers, which are produced only locally and are difficult to trade and store, will be consumed less by urban and wealthier populations compared with potatoes, which are generally traded and easily processed. This trend applies also to coarse grains such as millet and sorghum, which tend to be substituted by rice and wheat as income increases. We chose food groups to achieve consistent relationships between demand and per capita income, and thus our neglect of within-group reallocation should not affect our conclusions. However, an interesting extension to this research would be to capture this reallocation by including multistage budgeting in our demand system.

\section{References}

Adamopoulos, T. (2009). Do Richer Countries Have Higher Distribution Margins? mimeo, York University.

Alexandratos, N. (ed.) (1988). World Agriculture: Toward 2000. New York University Press.

Alexandratos, N. (ed.) (1995). World Agriculture: Towards 2010. Rome: Food and Agriculture Organization of the United Nations and John Wiley \& Sons.

Alexandratos, N. and Bruinsma, J. (2012). World Agriculture Towards 2030/2050: The 2012 Revision. Rome: Food and Agriculture Organization of the United Nations.

Bennett, M. K. (1941). Wheat in national diets. Wheat Studies, 18(2), 37-76.

Berthou, A. and Emlinger, C. (2011). The Trade Unit Values database. International Economics, 128, 97-117.

Bodirsky, B. L., Rolinski, S., Biewald, A., Weindl, I., Popp, A. and Lotze-Campen, H. (2015). Food demand projections for the 21st century. PLoS ONE, 10(11), e0139201.

Brown, B. W. and Walker, M. B. (1989). The random utility hypothesis and inference in demand systems. Econometrica, 57(4), 815-829.

Bruinsma, J. (ed.) (2003). World Agriculture: Towards 2015/2030. London: Earthscan Publications Ltd. 
Chavas, J.-P. and Segerson, K. (1987). Stochastic specification and estimation of share equation systems. Journal of Econometrics, 35(2-3), 337-358.

Cirera, X. and Masset, E. (2010). Income distribution trends and future food demand. Philosophical Transactions of the Royal Society B: Biological Sciences, 365(1554), 2821-2834.

Cooper, R. J. and McLaren, K. R. (1996). A system of demand equations satisfying effectively global regularity conditions. The Review of Economics and Statistics, 78(2), 359-364.

Cranfield, J. A. L., Hertel, T. W., Eales, J. S. and Preckel, P. V. (1998). Changes in the structure of global food demand. American Journal of Agricultural Economics, 80(5), 1042-1050.

Cranfield, J. A. L., Preckel, P. V., Eales, J. S. and Hertel, T. W. (2002). Estimating consumer demands across the development spectrum: maximum likelihood estimates of an implicit direct additivity model. Journal of Development Economics, 68(2), 289-307.

Drewnowski, A. and Popkin, B. M. (1997). The nutrition transition: New trends in the global diet. Nutrition Reviews, 55(2), 31-43.

Dubois, P., Griffith, R. and Nevo, A. (2014). Do prices and attributes explain international differences in food purchases? The American Economic Review, 104(3), 832-867.

FAO (2006). World Agriculture: Towards 2030/2050. Rome: Food and Agriculture Organization of the United Nations.

FAO (2015). FAOSTAT database. Retrieved December 30, 2015 from http: //www . fao . org/faostat/ en.

Fouré, J., Bénassy-Quéré, A. and Fontagné, L. (2013). Modelling the world economy at the 2050 horizon. Economics of Transition, 21(4), 617-654.

Gao, G. (2012). World food demand. American Journal of Agricultural Economics, 94(1), 25-51.

Gaulier, G. and Zignago, S. (2010). BACI: International Trade Database at the Product-level. The 1994-2007 Version. Working paper 2010-23, CEPII.

Godfray, H. C. J., Beddington, J. R., Crute, I. R., Haddad, L., Lawrence, D., Muir, J. F., Pretty, J., Robinson, S., Thomas, S. M. and Toulmin, C. (2010). Food security: The challenge of feeding 9 billion people. Science, 327(5967), 812-818.

Greene, W. H. (2011). Econometric Analysis. Harlow: Pearson, 7th edition.

Grigg, D. (1996). The starchy staples in world food consumption. Annals of the Association of American Geographers, 86(3), 412-431.

Guimbard, H., Jean, S., Mimouni, M. and Pichot, X. (2012). MAcMap-HS6 2007, an exhaustive and consistent measure of applied protection in 2007. International Economics, 130, 99-121.

Haley, M. M. (2001). Changing consumer demand for meat: The U.S. example, 1970-2000. In A. Regmi (ed.) Changing Structure of Global Food Consumption and Trade, number WRS-01-1 in Agricultural and Trade Report, chapter 5, (pp. 41-48). Washington, DC: U.S. Department of Agriculture.

Hanoch, G. (1975). Production and demand models with direct or indirect implicit additivity. Econometrica, 43(3), 395-419.

Havlík, P., Valin, H., Herrero, M., Obersteiner, M., Schmid, E., Rufino, M. C., Mosnier, A., Thornton, P. K., Bottcher, H., Conant, R. T., Frank, S., Fritz, S., Fuss, S., Kraxner, F. and Notenbaert, A. (2014). Climate change mitigation through livestock system transitions. Proceedings of the National Academy 
of Sciences, 111(10), 3709-3714.

Herrero, M., Havlík, P., Valin, H., Notenbaert, A., Rufino, M. C., Thornton, P. K., Blümmel, M., Weiss, F., Grace, D. and Obersteiner, M. (2013). Biomass use, production, feed efficiencies, and greenhouse gas emissions from global livestock systems. Proceedings of the National Academy of Sciences, 110(52), 20888-20893.

Hertel, T. W., Ramankutty, N. and Baldos, U. L. C. (2014). Global market integration increases likelihood that a future African Green Revolution could increase crop land use and $\mathrm{CO}_{2}$ emissions. Proceedings of the National Academy of Sciences, 111(38), 13799-13804.

KC, S. and Lutz, W. (2017). The human core of the shared socioeconomic pathways: Population scenarios by age, sex and level of education for all countries to 2100. Global Environmental Change, 42, 181-192.

Khoury, C. K., Bjorkman, A. D., Dempewolf, H., Ramirez-Villegas, J., Guarino, L., Jarvis, A., Rieseberg, L. H. and Struik, P. C. (2014). Increasing homogeneity in global food supplies and the implications for food security. Proceedings of the National Academy of Sciences, 111(11), 4001-4006.

Nelson, G. C., Valin, H., Sands, R. D., Havlík, P., Ahammad, H., Deryng, D., Elliott, J., Fujimori, S., Hasegawa, T., Heyhoe, E., Kyle, P., Lampe, M. V., Lotze-Campen, H., d'Croz, D. M., van Meijl, H., van der Mensbrugghe, D., Müller, C., Popp, A., Robertson, R., Robinson, S., Schmid, E., Schmitz, C., Tabeau, A. and Willenbockel, D. (2014). Climate change effects on agriculture: Economic responses to biophysical shocks. Proceedings of the National Academy of Sciences, 111(9), 3274-3279.

Oberländer, L., Disdier, A.-C. and Etilé, F. (2017). Globalisation and national trends in nutrition and health: A grouped fixed-effects approach to intercountry heterogeneity. Health Economics, 26(9), 1146-1161.

Ogundari, K. and Abdulai, A. (2013). Examining the heterogeneity in calorie-income elasticities: A meta-analysis. Food Policy, 40, 119-128.

O’Neill, B. C., Kriegler, E., Riahi, K., Ebi, K. L., Hallegatte, S., Carter, T. R., Mathur, R. and van Vuuren, D. P. (2014). A new scenario framework for climate change research: the concept of shared socioeconomic pathways. Climatic Change, 122(3), 387-400.

Périssé, J., Sizaret, F. and François, P. (1969). The effect of income and the structure of the diet. Nutrition Newsletter (FAO), 7(3), 1-9.

Pingali, P. (2007). Westernization of Asian diets and the transformation of food systems: Implications for research and policy. Food Policy, 32(3), 281-298.

Popkin, B. M., Adair, L. S. and Ng, S. W. (2012). Global nutrition transition and the pandemic of obesity in developing countries. Nutrition Reviews, 70(1), 3-21.

Preckel, P. V., Cranfield, J. A. L. and Hertel, T. W. (2010). A modified, implicit, directly additive demand system. Applied Economics, 42(2), 143-155.

Rimmer, M. T. and Powell, A. A. (1992a). Demand Patterns Across the Development Spectrum: Estimates for the AIDADS System. Working Paper OP-75, Monash University, Centre of Policy Studies/IMPACT Centre.

Rimmer, M. T. and Powell, A. A. (1992b). An Implicitly Directly Additive Demand System: Estimates for Australia. Working Paper OP-73, Monash University, Centre of Policy Studies/IMPACT Centre.

Rimmer, M. T. and Powell, A. A. (1996). An implicitly additive demand system. Applied Economics, 
28(12), 1613-1622.

Roberts, M. J. and Schlenker, W. (2013). Identifying supply and demand elasticities of agricultural commodities: Implications for the US ethanol mandate. The American Economic Review, 103(6), 2265-2295.

Seale, J. L., Jr. and Regmi, A. (2006). Modeling international consumption patterns. Review of Income and Wealth, 52(4), 603-624.

The World Bank (2015). Purchasing Power Parities and the Real Size of World Economies: A Comprehensive Report of the 2011 International Comparison Program. Washington, DC: The World Bank.

The World Bank (2016). World Development Indicators. Version 2016-August.

Tilman, D., Balzer, C., Hill, J. and Befort, B. L. (2011). Global food demand and the sustainable intensification of agriculture. Proceedings of the National Academy of Sciences, 108(50), 20260-20264.

Tilman, D. and Clark, M. (2014). Global diets link environmental sustainability and human health. Nature, 515(7528), 518-522.

Timmer, C. P., Falcon, W. P. and Pearson, S. R. (1983). Food Policy Analysis. Baltimore and London: The Johns Hopkins University Press.

UN Population Division (2013). World Population Prospects: The 2012 Revision, volume I: Comprehensive Tables. New York: United Nations.

Valin, H., Sands, R. D., van der Mensbrugghe, D., Nelson, G. D., Ahammad, H., Blanc, E., Bodirsky, B., Fujimori, S., Hasegawa, T., Havlík, P., Heyhoe, E., Kyle, P., Mason-D’Croz, D., Paltsev, S., Rolinski, S., Tabeau, A., van Meijl, H., von Lampe, M. and Willenbockel, D. (2014). The future of food demand: Understanding differences in global economic models. Agricultural Economics, 45(1), 51-67.

West, P. C., Gibbs, H. K., Monfreda, C., Wagner, J., Barford, C. C., Carpenter, S. R. and Foley, J. A. (2010). Trading carbon for food: Global comparison of carbon stocks vs. crop yields on agricultural land. Proceedings of the National Academy of Sciences, 107(46), 19645-19648.

World Food Programme (2015). International Food Aid Information System. Retrieved November 25, 2015 from http://www.wfp.org/fais/quantity-reporting.

Yu, W., Hertel, T. W., Preckel, P. V. and Eales, J. S. (2004). Projecting world food demand using alternative demand systems. Economic Modelling, 21, 99-129.

Zhou, D. and Yu, X. (2014). Calorie elasticities with income dynamics: Evidence from the literature. Applied Economic Perspectives and Policy, 37(4), 575-601. 